\title{
A República das Letras Europeia, 1500-2000
}

PETER BURKE

I

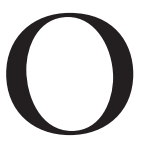

ESTUDO da Respublica litterarum do início da era moderna - a República das Letras, ou como prefiro chamá-la, a Comunidade do Saber [Commonwealth of Learning] -, de Erasmo a Diderot, tornou-se um tema bastante popular entre os historiadores nos últimos 30 anos. $^{1}$ É fácil perceber por quê. É sempre agradável ler sobre cooperação entre estudiosos.

A expressão respublica litterarum foi cunhada no século XV e permaneceu em uso regular desde a época de Erasmo, por volta de 1500, até o final do século XVIII. ${ }^{2}$ Essa comunidade moderna incipiente foi essencialmente uma comunidade imaginada, no sentido dado por Benedict Anderson (1983), às vezes descrita por meio de uma metáfora política ampliada em que a República conta com um senado, leis e outros implementos. Teria sido um estado igualitário imaginado, visto que houve tentativas de abolir ou, pelo menos, suspender distinções sociais entre os estudiosos proibindo-se demonstrações de deferência nos seus encontros. A imagem de uma república não era pura ficção, pois havia costumes e instituições que facilitavam a colaboração ou, pelo menos, a cooperação a distância, por exemplo, escrever cartas em latim, rompendo a barreira das línguas vernáculas europeias; fazer doações de publicações e informações; visitar outros estudiosos quando se viajava. As bibliotecas europeias costumavam ser abertas a visitantes estrangeiros. Mesmo em tempos de conflitos religiosos, que amiúde se transformavam em guerra, alguns estudiosos católicos e protestantes conseguiram manter boas relações pessoais e epistolares (Jaumann, 2001).

Um dos meios mais importantes para manter unida a Comunidade - como os jornais, no relato das nações feito por Anderson - foram os periódicos eruditos, como o famoso Nouvelles de la République des Lettres, editado por Pierre Bayle, que trazia notícias sobre o mundo culto - resenhas de livros novos, obituários de intelectuais e outras novidades do gênero.

Por volta do século XVIII, a Comunidade expandira-se para além da Europa e criara postos avançados em Batávia (atual Jacarta), Calcutá (atual Kolkata) e nas Américas, notadamente na Cidade do México, Lima, Boston, Filadélfia e Rio de Janeiro, onde uma Academia Científica foi fundada em 1772. ${ }^{3}$ A disseminação de comunidades de conhecimento de alcance mundial, ou pelo menos intercontinental, não começou na era da internet, embora tenha certamente se acelerado nos últimos 20 anos. 
Talvez nós hoje tendamos a achar que era tudo azul nessa comunidade, que a vejamos pelo filtro distorcido da nostalgia. Do ponto de vista social, a comunidade permaneceu restrita, praticamente confinada a homens das classes alta e média. Em teoria, a comunidade era igualitária, baseada no intercâmbio entre pares. Na prática, porém, alguns estudiosos eram mais iguais que outros. Havia mestres e discípulos, professores e aprendizes, patronos e clientes. A comunidade não era isolada do resto da sociedade - a sociedade hierárquica do Antigo Regime -, ainda que sob alguns aspectos representasse uma crítica a ela (à sua hierarquia e à rivalidade entre as nações).

Até aqui, eu apenas articulei o saber convencional, o consenso atual. Agora, porém, gostaria de ser mais subversivo. A maioria dos estudos sobre essa comunidade, real ou imaginada, chegou ao fim por volta de 1750 , com a Encyclopédie, ou em 1789 ou o mais tardar ao redor de 1800. O problema que eu gostaria de compartilhar com os leitores é saber se esse fim foi justificado ou prematuro. Pretendo argumentar que foi prematuro.

Há, naturalmente, algumas boas razões para essa decisão coletiva por parte da comunidade dos historiadores, mas elas não são suficientes, a meu ver. Os motivos principais são dois, que podem ser resumidos no mesmo número de palavras: nacionalismo e especialização.

As Guerras Napoleônicas tiveram impacto negativo sobre a alta cultura por provocarem uma ruptura nas comunicações. Embora no início franceses e britânicos respeitassem o axioma, como colocou Joseph Banks, presidente da Royal Society de Londres, de que "a ciência de ambas as Nações pode estar em Paz ainda que sua Política esteja em guerra", tal colaboração logo cessou. Banks surpreendeu-se quando um francês se recusou a visitá-lo em 1793. "Não posso conceber", escreveu, "que alguém possa considerar uma necessidade política privar-me do convívio de um intelectual por ser ele de uma nação com a qual estamos em guerra" (apud Gascoigne, 1988, p.155). Desse modo, a famosa observação de um cientista médico inglês, feita por volta de 1803, de que "As ciências nunca estão em guerra", já nascia ultrapassada (apud De Beer, 1960).

A harmonia da comunidade do saber estava cada vez mais ameaçada, não só pelas guerras, mas também, de maneira mais insidiosa, pela transmutação do cosmopolitismo em nacionalismo. No contexto intelectual, poder-se-ia até falar da "nacionalização" do conhecimento no século XIX, quando surgiu a noção de que o estudioso era um representante de seu país e poderia ser convocado para o serviço do Estado-nação.

Em termos mais concretos: verbas eram muitas vezes disponibilizadas pelo Estado para grandes empreendimentos culturais nacionais - museus nacionais, bibliotecas nacionais, dicionários de biografias nacionais, estudos geográficos ou geológicos nacionais, ou histórias da nação, sua língua e sua literatura. Por sua 
vez, as iniciativas culturais que carecessem dessa ressonância nacional recebiam menos apoio oficial.

O segundo ponto que corrobora o tradicional fim da história da comunidade do saber por volta de 1800 envolve a longa tendência de especialização intelectual, ou seja, a fragmentação da antiga República das Letras em províncias ou comunidades distintas de especialistas.

No decorrer do século XIX, as divisões entre as disciplinas foram sendo cada vez mais institucionalizadas e incorporadas em departamentos ou institutos, com muros separando-as dos demais "territórios e tribos acadêmicos" (Becher \& Trowler, 2001). A comunidade, tal como os campi que hoje a compõem, tornou-se um arquipélago de ilhas disciplinares. Como resultado dessas mudanças, a expressão république des lettres foi se tornando pouco a pouco restrita às belles-lettres. ${ }^{4}$

As tendências centrífugas descritas acima, tanto nacionais como disciplinares, foram, entretanto, contrabalançadas por algumas forças centrípetas.

\section{III}

Apesar do nacionalismo e da especialização, creio ser plausível restaurar a ideia de Comunidade do Saber para descrever a vida acadêmica no Ocidente desde 1800 e, mundialmente, a partir do final do século XIX. ${ }^{5}$ Com essa postura, estou evidentemente tentando subverter a tradicional separação entre os primórdios e o final da era moderna ou, pelo menos, promover o diálogo entre essas duas espécies ou tribos do historiador.

Gostaria, portanto, de sugerir a divisão da história da Comunidade do Saber em quatro períodos de duração extremamente desigual. O primeiro, o longo período do início da Modernidade, se estende de 1500 a meados do século XIX e pode ser descrito como a Era da Comunidade Puxada a Cavalo, uma vez que livros, cartas e os próprios estudiosos dependiam da força de cavalos para viajar.

O cavalo, é claro, foi igualmente dominante na Antiguidade e na Idade Média, de modo que poderíamos estender o primeiro período ainda mais para trás. Mas não o farei aqui, a despeito da importância de uma história das relações entre estudiosos de 500 a 1500 a.C. (uma história que até agora não foi escrita), por dois motivos. O primeiro é que a expressão respublica litterarum era desconhecida nesse período, sugerindo que os estudiosos não compartilhavam uma percepção de si como a que encontramos depois de 1500. O segundo motivo para iniciar a história por volta de 1500 (ou pouco antes) é, como não poderia deixar de ser, o surgimento da impressão com tipos móveis no Ocidente.

O segundo período, de 1850 a 1950, poderia ser designado a Era do Vapor, no sentido das viagens por ferrovias e navios a vapor. O terceiro, entre 1950 até quase o final do século XX, foi a Era do Jato, em que uma "intelligentsia jet set" viajava constantemente pelo mundo. Chegamos agora ao quarto período, a Era Eletrônica, marcado tanto pelas comunicações por e-mail como por sentimentos de culpa acerca da nossa "pegada de carbono" no planeta. 
Para evitar mal-entendidos, devo dizer aqui que não sou um determinista tecnológico. Simplesmente considero útil distinguir os períodos da história da comunidade do saber - que sempre foi essencialmente um sistema de comunicação - em termos da evolução das tecnologias de comunicação. As novas tecnologias sempre ofereceram oportunidades que alguns indivíduos e grupos souberam logo explorar.

Examinarei a seguir as três eras desde $1850 \mathrm{em}$ ordem temporal, observando de passagem os resquícios de uma época em outra, um fenômeno que obviamente não podemos esquecer quando construímos períodos históricos. Os dois últimos períodos, nos quais alguns de nós vivemos, podem nos parecer quase corriqueiros, por isso concentrarei a atenção na relegada Era do Vapor.

\section{IV}

Em alguns aspectos, o segundo período da comunidade do saber, a Era do Vapor, foi uma continuação do primeiro. A prática de escrever cartas continuou sendo importante e, de fato, o serviço postal internacional foi se tornando mais rápido, mais barato e mais confiável, graças não apenas às ferrovias, que transportavam cartas e pessoas, mas também à Conferência Postal de Berna de 1874 . As cartas passaram a ser complementadas por separatas, que se tornaram uma espécie de cartão de visita acadêmico, enviado para iniciar e manter relações com colegas estrangeiros.

Na verdade, porém, a comunidade foi transformada na Era do Vapor pelo surgimento dos congressos internacionais. Os estatísticos realizaram o seu primeiro encontro internacional em 1853, os químicos, em 1860, os médicos, em 1867, os geógrafos, em 1871, os historiadores da arte, os orientalistas - um termo que não era pejorativo naqueles dias - e os meteorologistas, em 1873, os geólogos, em 1878. Ao final do século, eram realizados em média cerca de 30 congressos desse tipo por ano. A comunidade de historiadores foi relativamente lenta em se organizar, mas o primeiro Congresso Internacional de Ciências Históricas foi realizado em Paris em 1900, o local tendo sido escolhido para coincidir com a Feira Mundial daquele ano (que também atraiu congressos de matemáticos, físicos, químicos, botânicos, geólogos, meteorologistas e psicólogos). ${ }^{6}$ A expansão simultânea das ferrovias e dos congressos internacionais não pode ser mera coincidência.

O navio a vapor também ajudou a transformar a comunidade, permitindo que a barreira transatlântica fosse quebrada na década de 1840 - o que tornou possível, por exemplo, as palestras nos Estados Unidos dadas por cientistas britânicos como Charles Lyell, Matthew Arnold e T. H. Huxley, e por estudiosos alemães como Karl Lamprecht, Ferdinand Tönnies, Ernst Troeltsch, Max Weber e Werner Sombart. Todos eles viajaram para os Estados Unidos por ocasião da Exposição Universal de St. Louis e lá permaneceram para dar palestras. Um programa regular de intercâmbio de professores visitantes entre Berlim e Harvard foi instituído em 1905. E, por volta de 1920, as bolsas Rockefeller estavam 
proporcionando a alguns jovens físicos europeus a oportunidade de trabalhar nos Estados Unidos.

Se adaptarmos as ideias de Walter Bagehot sobre a Constituição britânica, saberemos distinguir congressos "dignos" ou cerimoniais dos congressos "eficientes" ou funcionais. Alguns desses congressos do século XIX realmente fizeram uma diferença, notadamente a Convenção de Genebra de 1864 e a Conferência Internacional do Primeiro Meridiano de 1884, realizada em Washington. No caso da química e da estatística, os congressos internacionais ajudaram a padronizar terminologias e categorias. $\mathrm{O}$ mesmo foi provavelmente verdade para outras disciplinas, embora não para a história. Marc Bloch sonhava, em vão, persuadir seus colegas a padronizar termos técnicos, como feudalismo.

Naturalmente, os efeitos mais abrangentes ou mais profundos dos congressos de estudiosos são imponderáveis, mas eu me pergunto se um projeto internacional, como a Cambridge Modern History (1902-1912), pensado no final do século XIX por um inglês cosmopolita, lorde Acton, poderia ter sido realizado em um período anterior. Os congressos promoveram o que se chamou de "desnacionalização" da ciência, um antídoto à nacionalização mencionada anteriormente. Seu trabalho foi corroborado pela fundação de associações internacionais permanentes: de geodésia (1861), botânica (1901), sismologia (1903) e outras (Crawford et al., 1992).

Tais avanços tiveram o seu preço: o declínio das sociedades eruditas locais, por exemplo (antiquárias, arqueológicas, literárias e outras), ou no mínimo a perda de algumas de suas funções - ainda que muitas dessas sociedades tenham sobrevivido a duras penas até meados do século XX ou mesmo depois. Houve também um processo de "academicização", isto é, uma cisão cada vez mais acentuada entre os amadores (como os fidalgos rurais e os clérigos que tanto contribuíram para o conhecimento nos séculos XVIII e XIX) e os novos profissionais especializados. O surgimento de padrões formais, como a revisão por pares na publicação de artigos em periódicos profissionais, contribuiu para excluir não só as contribuições inferiores de correligionários, mas também as contribuições positivas de indivíduos de fora do grupo.

A grande linha de falha no seio da República, porém, parece ter sido aquela entre o que o Charles Snow (1959) (o químico inglês que virou escritor) chamou em 1959 de "as duas culturas". Na época de Snow, por sinal, os cientistas eram mais propensos do que os humanistas a se verem como uma comunidade (Hagstrom, 1965). O polímata anglo-húngaro Michael Polanyi, ecoando intencionalmente o uso mais antigo da expressão, referiu-se à "república da ciência". 7

A república da ciência foi se dividindo em um número cada vez maior de disciplinas, às vezes também descritas como comunidades. A ideia de uma "comunidade cristalográfica", por exemplo, ou da "comunidade da proteína" passou a competir com o termo mais amplo. Um dos motivos de eu preferir 
a expressão "Comunidade do Saber" a "República das Letras", especialmente quando se trata dos séculos XIX e XX, é a associação que existe (ao menos para um inglês) entre o termo "comunidade" [commonwealth] e uma federação flexível que permite múltiplas identidades.

É hora de mencionar algo sobre os fatores de ruptura na vida da República - os terremotos políticos. Desnecessário dizer que a ascensão do fascismo e do nazismo e as duas guerras mundiais foram desastres para o mundo do saber tanto quanto para o mundo em geral.

Alguns estudiosos expressaram um forte nacionalismo. Em 1914, 93 professores universitários alemães escreveram uma carta defendendo a queima da biblioteca da Universidade de Louvain (atual Leuven) (Johnson, 1990, p.1812). O grande historiador belga Henri Pirenne rompeu relações com seu examigo Karl Lamprecht na época da guerra, durante a qual o próprio Pirenne foi preso pelos alemães.

Por sua vez, certas reações a esses desastres revelaram a solidariedade mais ampla da comunidade. Após a guerra, Pirenne trabalhou arduamente para restaurar os Congressos Históricos Internacionais e readmitir os estudiosos alemães na comunidade de historiadores. Ele presidiu o Congresso de Bruxelas em 1923, onde apresentou a história comparativa como um antídoto ao nacionalismo. Mais ou menos na mesma época, a Liga das Nações estabeleceu um Comitê de Cooperação Intelectual (1922).

A ascensão do fascismo e do nazismo provocou, é claro, um grande êxodo de intelectuais da década de 1930 - o chamado êxodo dos estudiosos, a maioria deles judeus de língua alemã -, embora não devamos esquecer os antifascistas italianos e os espanhóis que emigraram para escapar da Guerra Civil (Kamen, 2007, p.260-321). Nesse caso, a solidariedade existente na comunidade manifestou-se na recepção dada a esses estudiosos na Grã-Bretanha, Estados Unidos, Suécia, Turquia, América do Sul e Nova Zelândia.

É hora de voltarmos para o terceiro período da República, entre as décadas de 1950 e 1990, a Era do Jato, cujos aviões mais velozes facilitaram a proliferação de pequenas conferências internacionais sobre temas específicos. Os grandes congressos disciplinares internacionais mencionados antes sobreviveram nesse período, e até se tornaram maiores, mas precisamente por esse motivo o verdadeiro trabalho passou cada vez mais a ser feito em outros lugares.

Sobre esse período, ressaltarei três pontos principais. O primeiro refere-se à participação das mulheres. Embora elas nunca houvessem sido banidas da comunidade, até o final do século XIX sempre atuaram em suas margens, fora das universidades - organizando salões, por exemplo (Goodman, 1994). Na Era do Vapor, que foi também a era da profissionalização, elas começaram a ingressar em universidades e conquistar títulos acadêmicos, incluindo doutorados. Na Era do Jato, seu número sempre crescente tornou-as muito mais visíveis, como pro- 
fessoras universitárias e autoras de livros e artigos eruditos - isso sem mencionar o movimento feminista.

Meu segundo ponto diz respeito à política na época da guerra fria. A Cortina de Ferro dividiu a comunidade, obviamente, como acontecera com a cisão entre católicos e protestantes e com as guerras religiosas no início do período moderno. Seja como for, porém, do mesmo modo que nos primórdios da era moderna, a comunicação entre eruditos continuou acima e além de qualquer desavença.

O contato pessoal entre indivíduos prosseguiu, por exemplo, como ilustra um fato curioso, que evoca a atmosfera da época. Em 1955, o historiador de Harvard Richard Pipes conheceu um pesquisador soviético no Congresso Internacional de Ciências Históricas em Roma e ambos passaram a trocar informações e livros entre si. O que hoje parece estranho é que Pipes sentiu a necessidade de confessar esse episódio para o FBI a fim de provar sua condição de americano leal (Diamond, 1992, p.58). Tenho as minhas próprias lembranças, extremamente vivas e totalmente inocentes, de visitas a colegas em Varsóvia, Cracóvia, Budapeste na década de 1960, seguidas de troca de correspondência e livros.

Em âmbito oficial, tomando estudos históricos como exemplo, a cortina às vezes entreabriu-se o suficiente para permitir conferências - por exemplo, entre historiadores franceses e poloneses -, para não falar na conferência anual de historiadores econômicos em Prato, onde os historiadores do outro lado da cortina sempre eram bem representados (creio que por insistência do prefeito da cidade, que normalmente era membro do Partido Comunista Italiano).

Mais uma vez, compensando em certa medida a divisão política da Europa, esse período começou com a fundação da Unesco (1946), que sucedeu o Comitê de Cooperação Intelectual, mas recebeu mais recursos do que seu antecessor. O cientista inglês Joseph Needham e o "gerente do conhecimento" americano Vannevar Bush foram algumas das pessoas que ajudaram a inserir o "s" [de scientific] na sigla Unesco, inicialmente concebida como uma organização para a cultura e educação, enquanto outro cientista inglês, Julian Huxley, se tornou seu primeiro diretor-geral. A Unesco também apoiou associações internacionais de ciências sociais e a produção de duas histórias universais em vários volumes, History of mankind (1963-), logo condenada como ocidentalizada e etnocêntrica, e sua sucessora History of humanity (1994-).

O surgimento do Mercado Comum, da Comunidade Europeia e da União Europeia também teve impacto sobre o terceiro período da Comunidade do Saber. Um exemplo óbvio é o Conseil Européen pour la Recherche Nucléaire (Cern) (1954), sediado em Genebra. É preciso reconhecer que a fundação do Cern foi motivada por necessidade financeira, visto que aceleradores de partículas não são baratos. Por sua vez, o Cern ajudou a criar uma comunidade europeia de cientistas - ou, no mínimo, de físicos de partículas. 
Também na exploração espacial a competição internacional foi substituída pela colaboração, impulsionada mais uma vez por questões financeiras. Em 1991, os Estados Unidos e a Rússia concordaram em construir uma estação espacial em conjunto. Do lado das humanidades, foi criado o Consórcio Europeu de Bibliotecas de Pesquisa (Cerl) (1992), arremedando o nome do Cern (ainda que sem seus recursos financeiros). A Fundação Europeia de Ciência (1974) dá dinheiro para projetos na área das humanidades, e também das ciências, servindo ao que chama de "comunidade europeia de pesquisa", um novo nome para a República das Letras. No caso da história, foram fundadas organizações de menor porte, como a Associação Europeia de História Urbana (1989) e a Sociedade Europeia de História Ambiental (1999).

Essa lista, que poderia ser facilmente ampliada, não pretende ser triunfalista. Tendo trabalhado na History of humanity da Unesco e participado de dois projetos financiados pela Fundação Europeia de Ciência, estou perfeitamente ciente dos aspectos negativos, e também positivos, das grandes organizações. O reverso da famosa observação "small is beautiful" ["pequeno é belo"] é "grande é feio", ou, mais precisamente, ineficiente, com dinheiro demais sendo gasto na administração ou em manter as aparências, restando muito pouco para os projetos em si - os males habituais da burocracia. Entre as organizações que conseguem evitar esse perigo estão os institutos internacionais de estudos avançados baseados no modelo de Princeton, entre eles o Nias em Wassenaar, Holanda (1970), o Wissenschaftskolleg em Berlim (1980), o Scass em Uppsala (1985) e o Instituto de Estudos Avançados (IEA) da USP, em São Paulo (1986), que promovem prolongados encontros face a face de estudiosos de diferentes países e disciplinas, que muitas vezes levam à inovação por meio da hibridação.

\section{VI}

Chegamos enfim ao quarto período, que começou há relativamente pouco tempo, cerca de 20 anos atrás, com a queda do Muro de Berlim e a disseminação da internet. Houve desde 1989 um "enorme crescimento na colaboração transnacional” (Crawford et al., 1992, p.4). Essa tendência foi fortalecida não só pelo degelo na política, mas também pela ascensão do inglês como o novo latim - vale lembrar que até a década de 1980 era quase impensável que estudiosos franceses falassem inglês, ao passo que este hábito é hoje corriqueiro.

O que transforma essas duas últimas décadas em um novo período, no entanto, é a ascensão do que se chamou a "República Digital do Saber" (Darnton, 2009b, p.3-20). O impacto das mudanças tecnológicas na vida cotidiana dos estudiosos é múltiplo e ainda difícil de avaliar. Por exemplo, as videoconferências vieram para ficar na década de 1990 e após minha palestra no IEA, que constitui o substrato deste artigo, recebi perguntas por e-mail de ouvintes fora da USP. As publicações online são outra inovação importante. As separatas, entregues em mão ou enviadas pelo correio, estão sendo substituídas pelo próprio artigo, publicado ou inédito, enviado por e-mail. As bibliotecas estão 
sendo transformadas, perdendo primeiro seus catálogos de fichas, substituídos por computadores, e depois seus periódicos, cada vez mais acessíveis online. E o Google Book Project pretende digitalizar milhões de livros e disponibilizá-los na internet (ibidem).

Ainda mais importante é a disseminação de microcomputadores e bancos de dados eletrônicos, não importa se os criamos nós mesmos ou se recorremos aos bancos já prontos dos mecanismos de busca. $\mathrm{O}$ trabalho online está transformando o que poderíamos chamar de "tempo de pesquisa", acelerando o diálogo entre colegas e a consulta a obras de referência, artigos eruditos e até mesmo certos arquivos. Ainda mais importante para a República, o trabalho online transforma o "espaço de pesquisa". Do ponto de vista geográfico, a importância dessas inovações é que elas podem ser utilizadas em diversos locais. A antiga distinção entre centros de conhecimento localizados em grandes cidades como Paris, Londres ou Nova York, e as províncias está finalmente sendo corroída. A célebre expressão de Marshall McLuhan, "aldeia global”, continua sendo um exagero, mas já é bem mais precisa do que em sua época (McLuhan faleceu em 1980).

Do ponto de vista social, o acontecimento mais notável, efetivamente imprevisível, foi a democratização da cooperação intelectual na Wikipédia. Seus artigos muitas vezes têm erros, mas a mesma crítica pode ser feita às enciclopédias impressas. O que distingue as enciclopédias online é a rapidez da sua revisibilidade, que é praticamente contínua. A Wikipédia é uma instituição que aprendeu muito, com extrema rapidez, e tem se tornado cada vez mais autocrítica. Diversos artigos aparecem acompanhados de advertências sobre saúde intelectual, por exemplo, "Este artigo precisa de fontes de referência adicionais para a verificação. Ajude a melhorar este artigo providenciando fontes fiáveis. Material sem apoio de fontes fiáveis pode ser contestado e removido".?

Ao lado das várias novas instituições mencionadas aqui, a Wikipédia mostra que, longe de estar morta, a Comunidade continua viva e atuante - embora, como todos nós, esteja longe de perfeita. Ela é um contraponto à ameaça para a República da Ciência representada pelas grandes empresas que insistem no sigilo e na propriedade intelectual, e tentam privatizar o conhecimento e impedir o seu fluxo.

A despeito da revolução tecnológica, minhas últimas palavras são dedicadas à continuidade. A tecnologia avança cada vez mais depressa, mas as instituições mudam menos rapidamente e as mentalidades coletivas ainda mais devagar. A continuidade é particularmente visível nas humanidades. A nova tecnologia ainda constitui um desafio para os estudiosos da minha geração, cujas pesquisas ainda se valem de fichários (os quais, aliás, tornaram-se objetos de espanto e admiração para pós-graduandos visitantes, verdadeiros vislumbres do passado). No terceiro período da República, os cientistas já tinham seus aceleradores de partículas, mas os humanistas ainda guardavam suas fichas em caixas de sapato e arquivavam suas xérox tamanho A4 em caixas de camisa. 
Embora as fichas possam estar obsoletas, outras tradições da República das Letras ainda sobrevivem e guardam seu valor. No futuro previsível, por exemplo, os livros impressos em papel coexistirão com os e-books e as bibliotecas continuarão armazenando-os e exibindo-os. ${ }^{10}$ Há também uma continuidade de ideais. As "leis" da República não só prevaleceram sobre as mudanças tecnológicas que dividem os quatro períodos, como também sobreviveram às guerras religiosas e à guerra fria: na verdade, elas se tornam mais visíveis em momentos de conflito ideológico.

A necessidade de contato pessoal para o progresso intelectual perdura na era digital. Os sociólogos do conhecimento têm sugerido que "na área de pesquisa, a transmissão de novas abordagens e competências quase sempre requer contato direto face a face" (Hoch \& Platt, 1992, p.133-52). O historiador francês Françoise Waquet (2003) certamente tem razão ao enfatizar num livro recente a persistência da oralidade na vida acadêmica - e que inclui, por certo, a palestra na qual este artigo se baseou. A minha presença recente na USP é um pequeno testemunho da sobrevivência da Comunidade.

Notas

1 Dentre os estudos mais importantes estão: Fiering (1976); Fumaroli (1988); Daston (1991); Goodman (1994); Goldgar (1995); Bots \& Waquet (1997); Jaumann ( 2001); Grafton (2009a, p.9-34).

2 Cf. Fumaroli (1988); Burke (1999).

3 On North America, Fiering, Transatlantic Republic.

4 Por exemplo, Casanova (1999).

5 Cf. Karady (1988, p.121-2). Embora ao contrário deste autor, Karady concentre-se nos alunos.

6 Cf. Crosland (1978, p.114-25); Erdmann (2005).

7 Cf. Polanyi (1946); De Jouvenel (1961, p.131-41).

$8 \mathrm{Ou}$, como o livro de Schumacher com este título foi traduzido em português, "o negócio é ser pequeno" (N.T.).

9 Wikipédia. Stalin. Consulta em 5.10.2009.

10 Cf. Darnton (2009a, p.43-58); Grafton (2009b, p.288-326).

\section{Referências}

ANDERSON, B. Imagined communities: reflections on the origins and spread of nationalism. London, 1983.

BECHER, A.; TROWLER, P. Academic tribes and territories: intellectual enquiry and the cultures of disciplines. Buckingham, 2001.

BOTS, H.; WAQUET, F. La république des lettres. Paris, 1997. 
BURKE, P. Erasmus and the republic of letters. European Review, v.7, n.1, p.5-17, 1999.

CASANOVA, P. La république mondiale des lettres. Paris, 1999.

CRAWFORD, E.; SHINN, T.; SÖRLIN, S. (Ed.) Denationalizing science. Dordrecht, 1992.

CROSLAND, M. P. Aspects of international scientific collaboration and organization before 1900. In: FORBES, E. G. A. (Ed.) Human implications of scientific advance. Edinburgh, 1978.

DARTON, R. The case for books. New York, 2009a. Google and the future of books. In: The case for books. New York, 2009b.

DASTON, L. The ideal and reality of the republic of letters in the Enlightenment. Science in Context, v.4, p.367-86, 1991.

DE BEER, G. The Sciences were never at war. London, 1960.

DE JOUVENEL, B. The republic of science. In: The logic of personal knowledge: essays presented to Michael Polanyi. London, 1961.

DIAMOND, S. Compromised campus: the collaboration of universities with the intelligence community, 1945-55. New York, 1992.

ERDMANN, K. D. Towards a global community of historians: the international historical congresses and the international committee of historical sciences, 1898-2000. Oxford, 2005.

FIERING, N. The transatlantic republic of letters. William \& Mary Quarterly, v.33, p.642-60, 1976.

FUMAROLI, M. The republic of letters. Diogenes, v.143, p.129-52, 1988.

GASCOIGNE, J. Science in the service of empire. Cambridge, 1988.

GOLDGAR, A. Impolite learning: conduct and community in the republic of letters, 1680-1750. New Haven, 1995.

GOODMAN, D. The republic of letters: a cultural history of the French Enlightenment. New York, Ithaca, 1994.

GRAFTON, A. A sketch map of a lost continent: the republic of letters. In: Worlds made by words: scholarship and community in the modern West. Cambridge MA, 2009a.

. Codex in crisis: the book dematerializes. In: Worlds made by words: scholarship and community in the modern West. Cambridge MA, 2009b.

HAGSTROM, W. O. The scientific community. New York, 1965.

HOCH, P.; PLATT, J. Migration and the denationalization of science. In: CRAWFORD, E.; SHINN, T.; SÖRLIN, S. (Ed.) Denationalizing science. Dordrecht, 1992.

JAUMANN, H. (Ed.) Die europäische gelehrtenrepublik im zeitalter des konfessionalismus. Wiesbaden, 2001.

JOHNSON, J. A. The kaiser's chemists: science and modernization in imperial Germany. Chapel Hill, NC, 1990.

KAMEN, H. The disinherited: the exiles who created Spanish culture. London, 2007. 
KARADY, V. La république des lettres des temps modernes. L'internationalisation des marchés universitaires occidentaux avant la Grande Guerre. Actes de la Recherche en Sciences Sociales, p.121-22, 1988.

POLANYI, M. Science, faith and society. Oxford, 1946.

SNOW, C. P. The two cultures. Cambridge, 1959.

WAQUET, F. Parler comme un livre. L'oralité et le savoir (XVIe-XXe siècle). Paris, 2003.

Peter Burke é historiador, professor do Emmanuel College Cambridge (Inglaterra), e autor de mais de 30 livros, muitos deles publicados no Brasil. Foi professor visitante do IEA-USP de setembro de 1994 a setembro de 1995, período em que desenvolveu o projeto de pesquisa "Duas crises de consciência histórica". @ - upb1000@cam.ac.uk

Palestra proferida pelo autor no dia 22 de setembro de 2010, no Instituto de Estudos Avançados da USP.

Tradução de Carlos Malferrari. O original em inglês - "The European Republic of Letters, 1500-2000" - encontra-se à disposição do leitor no IEA-USP para eventual consulta. 